\title{
Evolução temporal do processo de assoreamento da bacia do Parque Cesamar em Palmas/TO
}

Com o constante crescimento do processo de ocupação dos espaços geográficos, a superfície terrestre vem sofrendo imensas transformações que superam sua capacidade de se reestabelecer, assim, interferindo na intensidade e frequência em que ocorrem seus processos naturais. Entre os quais se destaca os processos erosivos, que devido à incrementação da ação antrópica vem acelerando seu surgimento, principalmente, no espaço urbano com as alterações nas características naturais de drenagem, assim como sua ausência e a impermeabilização do solo que trazem consigo sérias consequências ambientais como a degradação do solo e dos recursos hídricos. Deste modo, o presente estudo tem como objetivo analisar a evolução temporal do processo de assoreamento devido a ocorrência de erosões no entorno da bacia do Parque Cesamar em Palmas/TO e demonstrar os tipos de erosões atuantes na região. Além de propor novas medidas corretivas e preventivas. A metodologia aplicada a este projeto de pesquisa será o levantamento de dados bibliográficos como base cientifica para a análise temporal do avanço do assoreamento do lago até o ano de 2020 com o auxílio das ferramentas de geoprocessamento, que por meio de imagens de satélite será identificado o período em que o processo erosivo se instalou e o surgimento do assoreamento, anualmente, até 2020. Depois da conclusão do trabalho, espera-se demonstrar a influência que o processo de urbanização causa na formação de erosões em especial na bacia do Parque Cesamar e mostrar a necessidade de elaborar um plano de contingência que auxilie no controle dos danos ambientais que as erosões trazem consigo.

Palavras-chave: Erosão; Assoreamento; Geoprocessamento.

\section{Temporal evolution of the seeding process of the Cesamar Park basin in Palmas/TO}

\begin{abstract}
With the constant growth of the process of occupation of geographical spaces, the earth's surface has undergone immense transformations that surpass its capacity to re-establish itself, thus interfering in the intensity and frequency in which its natural's processes occur. Among which stands out the erosive processes, which due to the increase of anthropic action has been accelerating its appearance, mainly in the urban space with changes in the natural drainage characteristics, as well as its absence and the waterproofing of the soil that bring with it serious environmental consequences such as degradation of soil and water resources. Thus, the present study aims to analyze the temporal evolution of the silting process due to the occurrence of erosions around the Parque Cesamar basin in Palmas/TO and to demonstrate the types of erosions operating in the region. In addition to proposing new corrective and preventive measures. The methodology applied to this research project will be the collection of bibliographic data as a scientific basis for the temporal analysis of the advancement of the silting up of the lake until the year 2020 with the help of geoprocessing tools, which through satellite images will be identified. Period in which the erosion process took place and the emergence of silting up, annually, until 2020. After the conclusion of the work, it is expected to demonstrate the influence that the urbanization process causes in the formation of erosions, especially in the Parque Cesamar basin and to show the need to elaborate a new contingency plan that helps in the control of environmental damages that erosions bring with them.
\end{abstract}

Keywords: Erosion; Silting; Geoprocessing.

Topic: Engenharia de Recursos Hídricos

Reviewed anonymously in the process of blind peer.
Received: 12/07/2020

Approved: $20 / 10 / 2020$
Renan Henrique Araújo Marinho Souza

Faculdade Presidente Antônio Carlos, Brasil http://orcid.org/0000-0002-3189-8103 renan.rh3006@gmail.com

Diogo Pedreira Lima (iD)

Faculdade Presidente Antônio Carlos, Brasil http://lattes.cnpq.br/7967728577417186 http://orcid.org/0000-0002-3849-2587

diogo.lima@itpacporto.com.edu.br

\section{Referencing this:}

SOUZA, R. H. A. M.; LIMA, D. P.. Evolução temporal do processo de assoreamento da bacia do Parque Cesamar em Palmas/TO. Natural Resources, v.10, n.3, p.51-59, 2020. DOI: http://doi.org/10.6008/CBPC2237-9290.2020.003.0006 


\section{INTRODUÇÃO}

À medida que o processo de ocupação do espaço geográfico se desenvolve, o ser humano vem causando uma série de modificações na superfície terrestre por meio da retirada da vegetação, urbanização, impermeabilização do solo, entre outros. Desta forma, com as constantes transformações na superfície tornou-se comum a presença de processos erosivos acelerados que trazem consigo imensos problemas socioambientais, destacando-se a degradação dos recursos hídricos, a desertificação do solo e as grandes movimentações de massas, principalmente, na zona urbana.

Assim, os fenômenos associados aos processos erosivos são guiados em função de dois condicionantes: os fatores antrópicos, que estão relacionados com o processo de exploração dos recursos naturais, uso e ocupação do solo (obras civis, urbanização, agricultura, etc.) e os fatores naturais, que ditam a intensidade e o comportamento dos processos erosivos, como a chuva, a cobertura vegetal, a topografia e os tipos de solos (BRITO, 2012).

Desta forma o processo de erosão do solo pode ser entendido como um fenômeno natural pelos quais os materiais na superfície são degradados, desgastados e transportados devido à ação de agentes como o fluxo de água (enxurrada), o vento e o gelo. Podendo ocorrer de modo e intensidades diferentes conforme as características de cada paisagem com maior ou menor suscetibilidade erosiva (OLIVEIRA et al., 1998).

Segundo Guerra et al. (2012), os processos erosivos vêm ocorrendo de forma anomalia, sobretudo, nas regiões de clima tropical destacando-se o processo de formação da erosão do tipo hídrica. Que é um dos principais processos de degradação do solo, que possui grande poder de devastação, acarretando enormes prejuízos socioeconômicos e ambientais.

A erosão hídrica pode ser classificada em dois principais tipos: erosão laminar que se caracteriza pela remoção que ocorre uniformemente sobre a camada superficial do solo através do escoamento difuso das águas pluviais; E a erosão linear (sulcos, ravinas e voçorocas) são as efetivas transparências da concentração do escoamento superficial nas depressões da superfície durante o tempo. Desta forma, podemos mencionar como resultado deste fenômeno a perda de recurso natural, como o transporte de sedimentos e a degradação dos recursos hídricos por meio do assoreamento (LEPSCH, 2010).

Desta forma a erosão hídrica está diretamente ligado ao escoamento superficial, que é uma das fases pertencentes ao ciclo hidrológico de maior relevância para a engenharia. Visto que sua intensidade está relacionada com a capacidade de infiltração e a permeabilidade do solo, onde se estuda o deslocamento e o aproveitamento das águas superficiais (OLIVEIRA et al., 1998).

Segundo Tucci (2013), é possível distinguir os principais fenômenos que compõe a erosão hídrica que ocorre nas seguintes fases: desagregação das partículas de solo; transporte; sedimentação; disposição e consolidação das partículas de solo.

Desagregação - refere-se ao processo de desprendimento das partículas através do efeito de reações químicas, flutuação de temperatura, ações mecânicas e, principalmente, do efeito dos impactos das gostas de chuva no solo; 
Transporte - está relacionado como o transporte do material erodido pela água, que só ocorre quando o solo atinge seu ponto de saturação máxima ou quando a intensidade da precipitação excede a taxa de infiltração, dando origem ao escoamento superficial (enxurradas);

Sedimentação - é o processo em que as partículas de solo transportadas, se reestabelecem no fundo dos corpos hídricos pela ação da gravidade;

Disposição - ocorre quando a carga de sedimentos é maior do que a capacidade de transporte da enxurrada, ou seja, é a parada total da partícula em suspensão;

Consolidação - é o acúmulo de partículas sedimentadas sobre o fundo e a compactação desse depósito em razão do aumento da densidade das partículas depositadas.

Ainda de acordo Tucci (2013), devido o avanço da urbanização o escoamento superficial é intensificado pela falta de drenagem adequada, impermeabilização do solo, canalização ou obstrução do escoamento, podendo provocar um aumento de sua vazão em até seis vezes em relação as condições naturais. Desta forma, o potencial erosivo que é a capacidade de provoca ou causar erosão é aumenta substancialmente devido as perturbações no processo de escoamento superficial.

Com o avanço do uso e ocupação do solo devido a urbanização surgiu a necessidade de se acompanhar e/ou monitorar o desenvolvimento destes processos, principalmente, para dar um bom planejamento e um adequada orientação ao processo de ocupação, respeitando sua capacidade de suporte para a segurança da sociedade e preservação dos recursos naturais.

Estes fenômenos podem ser estudados por meio de técnicas de geoprocessamento, faz-se possível analisar espacialmente estes fenômenos, de maneira a auxiliar o correto planejamento de ações para uso e ocupação do solo. Além da possibilidade de apontar ou identificar locais que necessitam intervenções para o controle dos processos erosivos (ALVES, 2000, citado por MENDES et al., 2017).

Desta forma a área de estudo situa-se no Município de Palmas/TO e dentro do Parque Cesamar, onde o mesmo foi inaugurado em 1998, contendo $6 \mathrm{~km}$ de perímetro e uma barragem de $150 \mathrm{~m}$ de comprimento e 12 m de altura, assim, dando origem a um espelha d'água de 15,45 há e 2 m de profundidade. 0 entorno do parque é altamente urbanizado e com claras alterações em seu meio, como impermeabilização do solo, desmatamento de suas margens e atuação de processos erosivos localizados nas suas entradas de água de seus afluentes. Onde o lago do parque apresenta problemas de assoreamento como indica o PMSB (PALMAS, 2014), apontando como causador do mesmo a presença de processos erosivos em seu entorno e dando apenas como alternativa para solucionar o problema o seu monitoramento e dragagens, quando necessário.

Que em 2014 a Prefeitura Municipal de Palmas seguindo as orientações do Plano Municipal de Saneamento Básico (PMSB), concretizou obras desassoreamento do referente lago. Porém, mesmo tomando as devidas recomendações do plano, ainda é evidente a continuação do assoreamento do lago o que demostra a necessidade de analisar e identificar os processos erosivos atuantes, assim, como o planejamento de novas mediadas corretivas e preventivas.

Em consideração as informações descritas acima, podemos dizer que em períodos chuvosos a uma grande tendência de os processos erosivo gerar ou provocar a perda de solo, assim, dando origem a um fluxo 
de cargas solidas (sedimentos) devido ao escoamento das águas pluviais e consequentemente o assoreamento do corpo hídrico com a consolidação dessas partículas. Neste contexto, o presente trabalho objetiva analisar a evolução temporal do processo de assoreamento devido a ocorrência de erosões no entorno da bacia do Parque Cesamar em Palmas/TO, com o intuito de analisar e demonstrar os tipos de erosões atuantes na região e propor novas medidas corretivas e preventivas.

\section{METODOLOGIA}

Como o intuito de analisar o comportamento temporal do processo de assoreamento do lago do parque Cesamar, esta pesquisa foi dividida em três etapas: a primeira etapa consiste em analisar/interpreta e classificar as imagens de satélite através do Software Earth Pro, procurando delimitar uma área de interesse para classificar a série temporal correspondente; a segunda etapa refere-se ao levantamento de campo, onde foi realizado um reconhecimento da área em questão e identificado pontos onde há a existência de erosões conforme interpretado nas imagens obtidas; a terceira consiste em analisar a expansão do assoreamento do lado do Parque Cesamar de forma que evidencie o avanço deste processo.

Para a primeira etapa, utilizou-se de base cartográfica necessária à elaboração do estudo compõe-se do banco de imagens de satélite disponíveis no Software Google Earth Pro e suas ferramentas disponíveis, modelos digitais de elevação (MDEs) do banco de dados da plataforma do Earth Explorer e Shuttle Radar Topograph Mission (SRTM). Além das imagens de satélite, utilizou-se também o Software Quantum GIS 3.12 (QGIS) para a geração de curvas de níveis que demonstram o perfil de elevação da área de interesse. Que para a delimitação da área de interesse pertinente ao Parque Cesamar fez-se o uso do banco de imagens disponíveis no Software Google Earth Pro. A escolha deste banco de dados se deu pelo fato de possibilitar analisar imagens recentes da área em questão com resolução satisfatória à pesquisa.

Inicialmente foi delimitado a área de interesse equivalente a $4 \mathrm{~km}^{2}$, onde foram analisados alguns seguimentos há serem confirmados na pesquisa de campo, como pontos suscetíveis a desenvolver ou que estão desenvolvendo processos erosivos e pontos onde a concentração do fluxo das águas pluviais. A parti da delimitação da área de interesse foi gerado um arquivo em formato KML para posteriormente ser importado para o programa QGIS 3.12 e para a plataforma do Earth Explorer e obter as imagens como dados digitais de elevação por meio dos modelos de elevação SRTM em formato GeoTIFF para a geração das curvas de níveis. Então, procedeu-se a execução dos seguintes procedimentos: 1. Adicionar à camada raster SRTM da área de estudo em formato Geo TIFF; 2. Adicionar a camada vetorial da delimitação da área em formato KML; 3. Extrair o recorte da área delimitada pela camada vetorial e exporta em formato Geo TIFF; 4. Abrir a camada raster do recorte da área delimitada; 5 . Extrair contorno da camada raster como equidistância de 20 m e exporta o arquivo em formato shapefiles (SHP).

A curva de nível foi gerada com o intuito de analisar a topográfica da região em estudo e verificar pontos que tendem a concentrar o fluxo das águas pluviais. Além de favorecer a identificação de pontos passiveis a desenvolver erosões, levando em consideração um dos condicionantes dos processos erosivos como fator topográfico que podem influenciar no desenvolvimento e formações de erosões em função da 
declividade e comprimento de rampa.

A segunda etapa da pesquisa, foi o levantamento de campo realizado no dia 12/03/2020 com o intuito de se realizar a confirmação e identificar de processos erosivos que estejam provocando o transporte de sedimentos, e o consequente assoreamento do lago. Conforme identificado na análise/interpretação da área de interesse. Para tal, utilizou-se os seguintes equipamentos: Câmera Fotográfica para registras as erosões instaladas e para mapear estes pontos utilizou-se do GPS Garmim Etrex H para anotar suas localizações que posteriormente forma introduzidas no banco de dados do Software Google Earth Pro.

Para a terceira etapa, utilizou-se de uma série temporal obtida a partir do banco de imagens de satélite do Software Google Earth Pro. Quanto a verificação da evolução do transporte de sedimentos no lago do Parque Cesamar, foram utilizadas imagens nas seguintes datas: 10/06/2013; 02/07/2014; $19 / 05 / 2013$; 20/04/2016; 30/04/2017; 28/04/2018; 13/05/2019 e 14/01/2020. As imagens foram classificadas com a mesma escala de forma a estabelecer um padrão único para as imagens, assim, possibilitando evidenciar o processo de assoreamento sem distorções. O período da série temporal foi determinado a partir do momento que se identificou a ação do transporte de sedimentos e acumulo do mesmo as margens do lago do parque.

Para a verificação da expansão do assoreamento, utilizou-se da mesma serie temporal obtido pelo Software Google Earth Pro que por meio do mesmo foi realizado a comparação entre área ocupado pelo assoreamento do recurso hídrico entre os anos de 2013 a 2020. Então, procedeu-se a execução dos seguintes procedimentos: 1. Na ferramenta 'Linha do tempo', inserir a data correspondente a imagem que se deseja analisar; 2. Estabelecimento da altura de visão em $1.60 \mathrm{~km}$ e da escala em $300 \mathrm{~m}$; 3. Com a ferramenta 'Polígono', medir o perímetro e a área correspondente ao avanço do assoreamento.

Estes procedimentos formam realizadas para todas as imagens classificadas, onde a finalidade deste roteiro e garantir que os resultados adquiridos com as análises estejam alinhados com a realidade, assim, evitando distorções no resultado final da interpretação. A comparação da análise temporal ocorreu a partir de uma escala de tempo deslizante de forma que demonstre as transformações que ocorreram devido ao transporte de sedimentos entre os anos de 2013 e 2020 no lago do Parque Cesamar e demonstre o avanço progressivo do assoreamento.

\section{RESULTADOS}

Como resultado da primeira etapa do projeto, na interpretação das imagens de satélite e da geração da curva de nível, identificou-se que nas proximidades do lago do Parque Cesamar a presença de grandes declividades e depressões nas coordenadas UTM: 8870928 de latitude Sul e 794257 de longitude Oeste; 8870274 de latitude Sul e 794215 de longitude Oeste; 8870312 de latitude Sul e 794123 de longitude Oeste. Assim, na segunda etapa com o intuito de realizar o reconhecimento da área e de checar a presença de erosões nos pontos elencados na primeira etapa, foi constato por meio do levantamento de campo a presença e identificação de processos erosivos nas coordenadas mencionadas acima com demostrado na figura 1. 


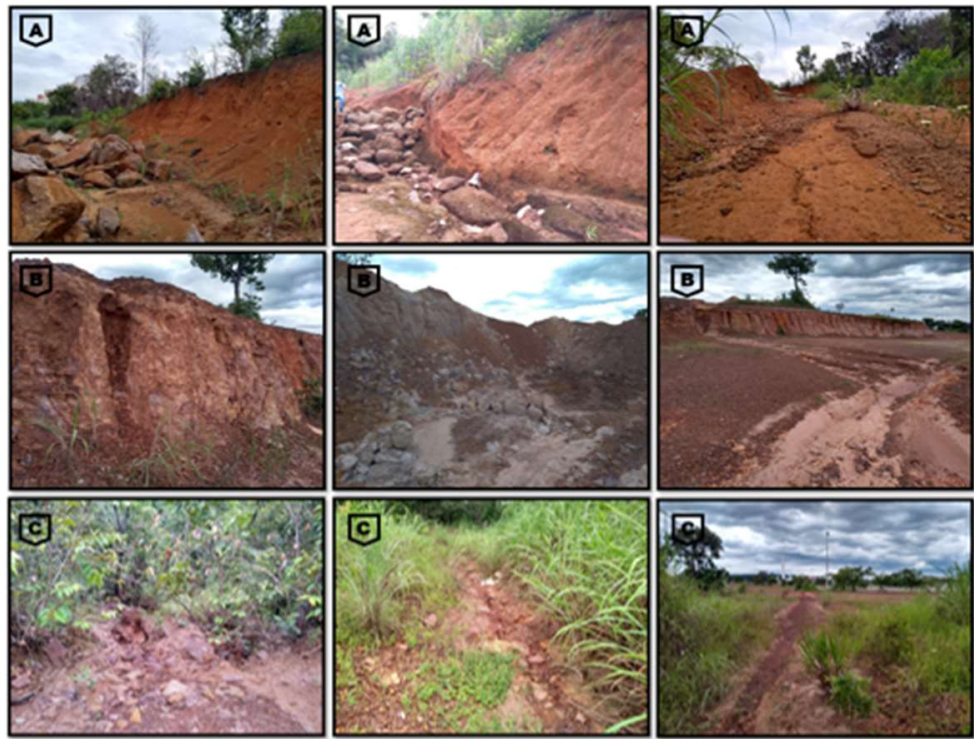

Figura 1: Identificação dos processos erosivos. (A) Ponto de monitoramento 01; (B) Ponto de monitoramento 02; (C) Ponto de monitoramento 03.
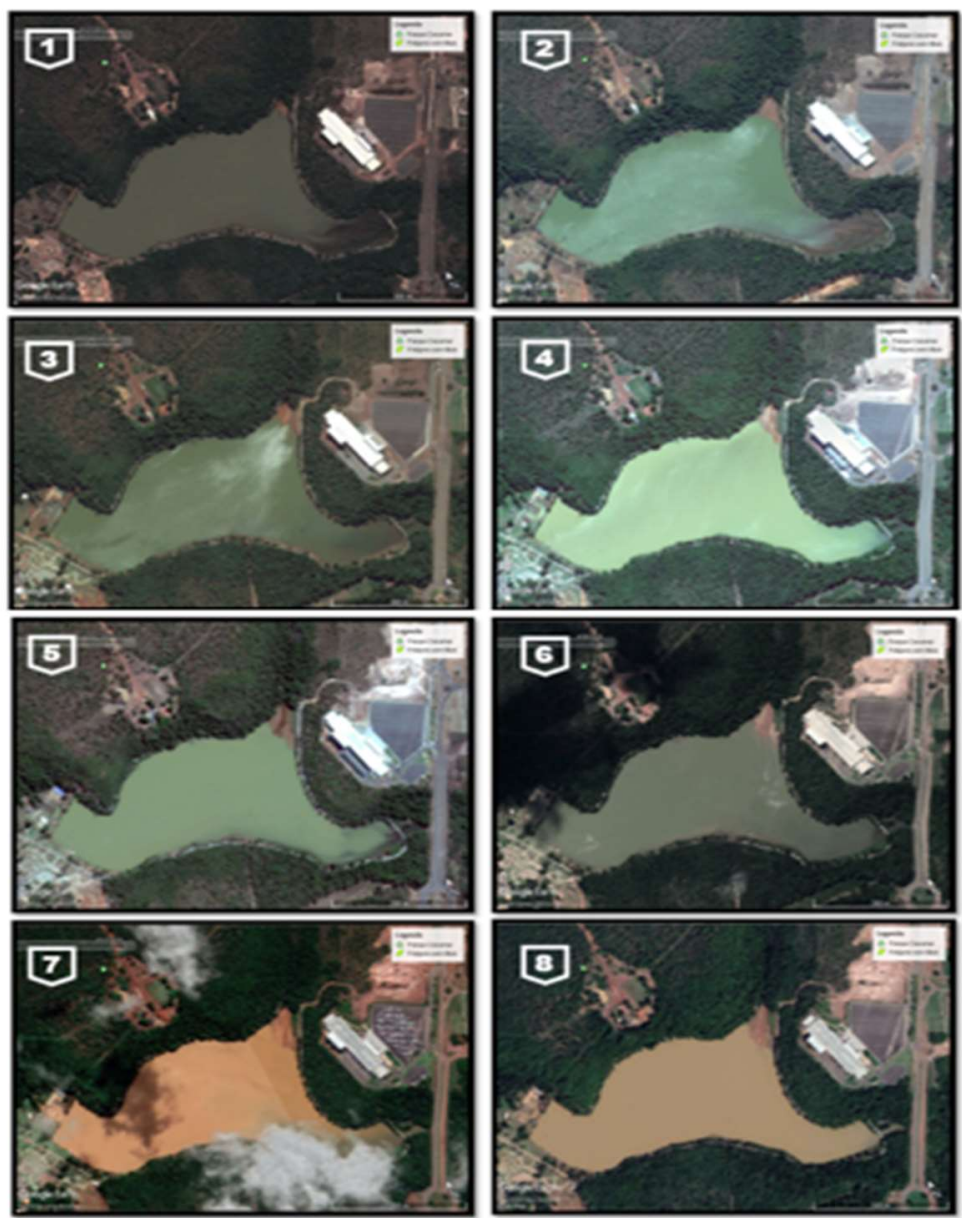

Figura 2: Evolução temporal do processo de assoreamento do lago do Parque Cesamar. Cada número representa uma data especifica, sendo (1) para 10/06/2013; (2) para 02/07/2014; (3) para 19/05/2013; (4) para 20/04/2016; (5) para 30/04/2017; (6) para 28/04/2018; (7) para 13/05/2019; (8) para 14/01/2020

$\mathrm{Na}$ terceira etapa, afim de verificar o avanço do processo de assoreamento foi analisado de forma temporal as imagens considerando a partir da identificação visual do assoreamento do lago por satélite. Assim, foram considerados os anos de 2013 a 2020, cada imagem foi denominada por uma numeração de 1 a 8 correspondente ao ano cada imagem como demonstrado na figura (2) e exposta de maneira que evidencie o avanço do assoreamento do lago ao decorrer dos anos. 
Os resultados obtidos a partir da análise temporal da evolução do assoreamento do lago em conjunto como os dados pluviométricos da estação Palmas/TO (83033) do banco de dados meteorológicos do Instituto Nacional de Meteorologia (INEMT), foi possível estabelecer uma relação entre o avanço do assoreamento do lago e os índices pluviométricos correspondente entre os anos de 2013 a 2020.

Todos dados obtidos da analise temporal do avanço do processo de assoreamento do lago, foi levando em conta a diferença de um ano após o outro, assim, tendo uma estimativa de quanto foi assoreado ano após ano. Que em conjunto com os dados pluviométricos possibilitando identificar a alteração do processo de arraste de partículas do solo em função do tipo e intensidade da precipitação atuante na região em estudo. Como demonstrado na figura (3).

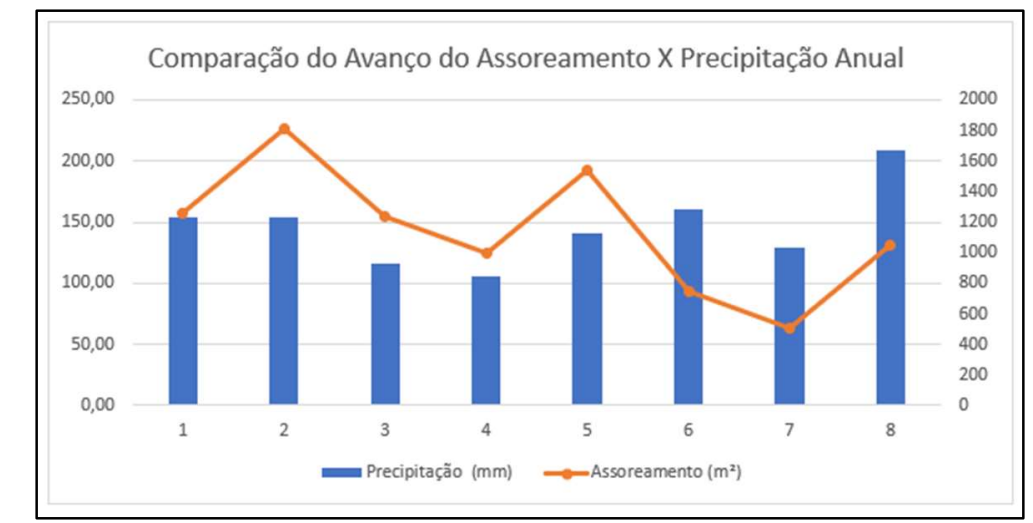

Figura 3: Relação do processo de assoreamento com os índices de precipitação anual.

\section{DISCUSSÃO}

Como demonstrado nas imagens (A), (B) e (C) da figura (01), é evidente a presença de erosões instalados ao entorno do Parque Cesamar como afirma o PMSB (PALMAS, 2014), principalmente erosões do tipo laminar por apresentar sinais de arraste ou transporte de material evidenciados na figura (01), que é umas das características deste tipo de erosão.

Na figura (01) é possível notar que devido as características do relevo e do solo presentes na região da imagem (A), o processo de arraste e menos acentuado do que demonstrado na imagem (B), onde há presença de solo arenosa que por sua vez são facilmente erodidos por não possuírem coesão. Nesta mesma região da imagem (B) foram constatados também a formação de ravinas devido à alta erodibilidade da região. Já na figura (C) foi constatado as mesmas situações do que na região da figura (B), mas com uma diferença, a presença de ravinas e devido a densidade e velocidade do escoamento superficial que é influenciada pela grande declividade da região deste ponto.

Estas variações nos processos de arrastes e o evolução das erosões se dá por um conjunto de fatores ligados a declividade do terreno e o tipo de solo existente na região como solos siltosos e arenosos. Que segundo Lepsch (2010), o caráter topográfico de determinada região pode influenciar os processos erosivos em função da declividade e o comprimento de rampa que alteram a velocidade do escoamento superficial, assim, como a morfologia dos solos. Que de acordo como Oliveira et al. (1998), os processos erosivos não se comportam da mesma forma em todos os tipos de solos, a uma grande gama de propriedades como a 
textura, estrutura, permeabilidade e densidade que conferem diferentes vulnerabilidades à erosão.

Com a análise temporal é possível notar na figura (02) um avanço significativo do processo de assoreamento entre os anos de 2013 a 2014 como demonstrado na imagem (1) e (2), onde foi o período em que ocorreu as denúncias relativas ao assoreamento do lago e com a constatação do problema. Além da execução do processo de dragagem conforme as recomendações do PMSB (PALMAS, 2014). Nas demais imagens e possível notar um avanço uniforme no processo de assoreamento como visto nas imagens 3, 4, 5, 6, 7 e 8 o que indicam que as recomendações do PMSB que é apenas o processo de monitoramento e desassoreamento (dragagem) não são apropriadas para a resolução deste problema.

Vale ressaltar que nas imagens da figura 2, é possível notar que a área que circunda o Parque Cesamar possui em sua boa parte a cobertura de vegetação nativa. O que implica ainda mais a presença de erosão laminar na região, caracterizado pelo transporte de carga solida por arraste onde maior quantidade de material grosso e fino são transportados até as margens do lago.

Por último, com os resultados obtidos a partir da análise temporal em conjunto como os dados pluviométricos do INEMT, indicam um avanço significativo do assoreamento do lago, principalmente, nos anos de 2014, 2015 e 2017 com demonstrado na Figura (3). Além de indicar uma oscilação neste processo de assoreamento conforme o tipo de precipitação, independente do indicie pluviométrico anual.

Que segundo Collischonn et al. (2013), a chuva é um fator climático que exerce grande influência nos processos erosivos, com destaque no processo laminar. Pois precipitações de grandes intensidades e curtos ou longos tempos de duração fornecem a energia suficiente para provocar a desagregação do solo e com o caráter topográfico da região apresenta grandes declividades o escoamento superficial e intensificado, dando, assim mais poder ao processo de arraste das partículas de solo até o lago do Parque Cesamar.

Deste modo podemos dizer que estas áreas estão influenciando diretamente no processo de assoreamento do lago do Parque Cesamar. Onde segundo Mendes et al. (2017), a perda de solo por erosão do tipo laminar na bacia de contribuição do Parque Cesamar e de 85,2688 t/ha.ano o que se pode classificar a erosão como média a forte. Por fim, pode-se afirmar que os resultados obtidos por esta pesquisa, demonstram a importância de realizar um novo plano de contingência, pois os previstos pelo PMSB não é o mais adequado para este tipo problema.

\section{CONCLUSÕES}

Por meio da análise temporal do processo de assoreamento e a utilização das ferramentas de geoprocessamentos foi possível demonstrar o avanço significativo do assoreamento do lago do Parque Cesamar entre os anos de 2013 a 2020. Este processo está ocorrendo progressiva devido a influência de alguns fatores como a declividade e o tipo de solo da região, além da interferência antrópica e principalmente por processos erosivos do tipo laminar instalados em locais favoráveis à sua evolução.

Apesar da existência de boa faixa de cobertura vegetação nativa ao entorno do parque, o que em suma age com proteção natural dos hídricos. Os processos erosivos que estão causando a perda de material estão instalados em pontos onde a concentração do fluxo do escoamento das águas pluviais (saídas d'águas), 
que por sua vez não possuem equipamentos de dissipação de energia essenciais o que diminuiria a agressividade das erosões e o poder de transporte das partículas de solo. Desta forma evidenciando a relação que existe entre as interferências antrópicos com a presença de processos erosivos acelerados ou anômalo.

Desta forma, para uma redução e prevenção da erosão laminar, recomenda-se a utilização de técnicas de intervenções físicas, modificando a morfologia do terreno nestes pontos onde a concentração das enxurradas. Que de acordo como Guerra et al. (2013) diminuiria a agressividade agente erosivo e diminuiria a capacidade de transporte da carga solida com a o desvio ou condução das águas pluviais, diminuindo a declividade do terreno com o processo de retaludamento ou com a colocação de obstáculos que dissipem a energia criado pelo escoamento superficial. Além de manter o monitoramento da região próxima ao lago do parque como previsto no PMSB.

\section{REFERÊNCIAS}

BRITO, A. O.. Estudos da erosão no ambiente urbano, visando planejamento e controle ambiental no Distrito Federal. Dissertação (Mestrado em Engenharia Florestal) Universidade de Brasília, Brasília, 2012.

COLLISCHONN, W.; DORNELLES, F.. Hidrologia para engenharia e ciências ambientais. 2 ed. Porto Alegre: Abrh, 2013.

GUERRA, A. T.; SILVA, A. S.; BOTELHO, R. G. M.. Erosão e conservação dos solos: conceitos, temas e aplicações. 8 ed. São Paulo: Bertrand Brasil, 2012.

GUERRA, A. J. T.; JORGE, M. C. O.. Processos erosivos e recuperação de áreas degradadas. 2 ed. São Paulo: Oficina de Textos, 2013.

LEPSCH, I. F.. Formação e Conservação dos solos. 2 ed. São Paulo: Oficina de Textos, 2010.
MENDES, F. C.; PEREIRA, H. L.; ZUKOWSKI, J.. Estimativa da perda de solo por erosão laminar na bacia do Parque Cesamar em Palmas/TO. Revista Integralização Universitária, Palmas, v.12, n.16, p.103-115, 2017. DOI: https://doi.org/10.31501/1982-9280.2017V11N16

OLIVEIRA, A. M. S.; BRITO, S. N. A.. Geologia De Engenharia. São Paulo: Associação Brasileira de Geologia de Engenharia, 1998.

PALMAS. Prefeitura Municipal de Palmas. Plano Municipal de Saneamento Básico de Palmas/TO. Palmas: Secretaria de Assuntos Jurídicos, 2014.

TUCCI, C. E. M.. Hidrologia: Ciência e Aplicação. 4 ed. Porto Alegre: UFRGS, 2013.

A CBPC - Companhia Brasileira de Produção Científica (CNPJ: 11.221.422/0001-03) detém os direitos materiais desta publicação. Os direitos referem-se à publicação do trabalho em qualquer parte do mundo, incluindo os direitos às renovações, expansões e disseminações da contribuição, bem como outros direitos subsidiários. Todos os trabalhos publicados eletronicamente poderão posteriormente ser publicados em coletâneas impressas sob coordenação da Sustenere Publishing, da Companhia Brasileira de Produção Científica e seus parceiros autorizados. Os (as) autores (as) preservam os direitos autorais, mas não têm permissão para a publicação da contribuição em outro meio, impresso ou digital, em português ou em tradução. 